\title{
DE LA NATURALEZA Y LOS NATURALES AMERICANOS EN EL SIGLO XVI: ALGUNAS CUESTIONES CRITICAS SOBRE LA OBRA DE FRANCISCO HERNANDEZ
}

POR

\author{
JESUS BUSTAMANTE GARCIA
}

\section{UN HUMANISTA Y UNA MISIÓN CIENTÍFICA: VOLUNTADES INSPIRA- DORAS DE UN PROYECTO}

La persona y la obra del doctor Francisco Hernández, médico de Su Majestad y protomédico general de todas las Indias, constituyen un ejemplo extremo de los problemas críticos que suelen rodear a buena parte de las figuras centrales del siglo XVI español. En el caso que nos ocupa se trata de un personaje y de una obra que destacan reconocidamente en el panaroma de su época: es el primer estudioso con una sólida formación científica que exploró la naturaleza del Nuevo Mundo y su obra, aunque sujeta a largos abatares y dilaciones, constituyó un gran reservorio del que los naturalistas europeos se nutrieron hasta el mismo siglo XIX. Sin embargo, y a pesar de que existe una amplia bibliografía, obra y autor están rodeados de un aura en la que la vaguedad de los sobreentendidos aceptados por todos viene a suplir la falta efectiva de conocimientos precisos (1).

De Hernández mismo, sobre el que Germán Somolinos ha llegado a elaborar una biografía monumental de referencia obligada (2), lo cierto es que la mayor parte de lo que sabemos

(1) Este estudio surgió dentro del marco de un amplio seminario de investigación coordinado por el Dr. Fermin del Pino que, con el título de "Ensayos sobre la contribución española a la ciencia moderna: la Historia Natural y Moral de las Indias", se desarrolló en el Depto. de Historia de América del Centro de Estudios Históricos del CSIC en 1985-86. Aunque desde entonces mi investigación ha avanzado mucho, he querido respetar aqui al menos, una parte del texto entonces presentado para poder reflejar mejor los interesantes planteamientos y propuestas que en ese seminario se llegaron a definir. Agradezeo especialmente al Dr. Fermín del Pino los largos y detallados comentarios que en su momento hizo a las primeras versiones escritas de este texto.

(2) Germán Somolinos D'ARdois: "Vida y obra de Francisco Hernández", vol. I de las Obras Completas de Francisco Hernández, México, UNAM, 1960. 
sobre su vida no es sino un esbozo hipotético que se sintetiza en las siguientes líneas.

Nació en la Puebla de Montalbán (Toledo) hacia 1517-18, pero lo ignoramos todo sobre su origen y familia. Inició sus estudios de medicina probablemente entre 1535-40, pero ignoramos dónde así como el curriculum preciso: tradicionalmente se venía suponiendo que fue en la Universidad de Salamanca, pero Somolinos ha planteado como más probable la de Alcalá. Por referencias indirectas que aparecen en sus escritos, sabemos que aproximadamente entre 1550 y 1555 residió al menos en Torrijos (Toledo) y en Sevilla, estando además de paso por Cádiz, Córdoba y Granada. Igualmente sabemos que por esas mismas fechas aproximadas contrajo matrimonio: con Juana Díaz de Paniagua; tuvo dos hijos (Juan Fernández y María de Sotomayor) y muy pronto se quedó viudo.

Sin que sepamos cuándo, aunque Somolinos supone que hacia 1557-60, residió y ejerció como médico en el monasterio jerónimo de Guadalupe, famoso por sus anatomizaciones, su jardín botánico y su hospital (y cuyos médicos se contaban entre los de más prestigio y sueldo de España). Hacia 1563 se trasladó a Toledo y hasta 1569 trabajó en el Hospital de Santa Cruz. Por entonces, y siendo ya viudo, tuvo una hija natural (Francisca Hernández) con una mujer soltera. Se supone que hacia el final de este período debió trasladarse a Madrid, probablemente por haber sido nombrado médico de la Corte.

Como puede observarse la imprecisión general de las informaciones nos impide saber cuál fue el verdadero trasfondo de sus actividades durante este período, actividades entre las que se cuentan ya la traducción o adaptación de obras clásicas filosóficas y naturalistas (como las primeras versiones de Plinio y de Aristóteles, entre otras). Por esos escritos tempranos, en buena parte aún inéditos, Hernández aparece como un médico con una profunda formación humanística y una notable preocupación que más que "religiosa" habría que denominar "moral» o "filosóficomoral», inscrito en una corriente de pensamiento "ecléctica» 0 , al menos, de difícil clasificación.

No menos grave es que tampoco sepamos cuál fue el círculo de personas que lo rodeaban por esos años, aunque nos consta que al menos ha conocido y tratado al gran anatomista Andrea Vesalio, que fuera médico del Emperador Carlos $\mathrm{V}$ y de su hijo Felipe II, y también es seguro que por entonces era ya amigo personal de figuras tan destacadas como Arias Montano y Juan 
de Herrera. Me parece muy importante señalar que probablemente a esos nombres haya que agregar además el del Cardenal Diego de Espinosa, en cuyo poderoso círculo se inscribían precisamente Juan de Ovando y Pedro Moya de Contreras, dos personajes decisivos para la futura actividad americana de Hernández, con los que éste mantuvo relaciones y, al menos con el segundo, también una estrecha amistad.

Sin que sepamos antecedentes o razones, en el mismo contexto de reforma de la administración americana que llevó a que Juan de Ovando pasara de visitador a presidente del Consejo de Indias y a que Pedro Moya de Contreras fuera designado arzobispo y primer gran inquisidor de México, Francisco Hernández fue nombrado el 11 de enero de 1570 protomédico general de todas las Indias y recibió el encargo especial de hacer la historia natural de las nuevas tierras. Esa actividad le mantuvo en suelo mexicano desde 1571 a 1577, constituyendo el período mejor conocido de su vida.

En 1578, vuelto ya de México y asentado en Madrid, enfermó gravísimamente e hizo testamento. Este es el motivo por el que algunos autores supusieron que entonces debió terminar la vida del protomédico, lo que además permitía explicar fácilmente los largos abatares que afectaron a la publicación de su obra, sobre la que el protomédico perdió el control al menos desde 1580. Sin embargo lo cierto es que Hernández no sólo sanó de esa enfermedad, sino que en el mismo año de 1578 fue nombrado médico del infante Felipe (futuro Felipe III). Ahora bien, a partir de este momento ignoramos cuál fue su actividad y el único dato posterior conocido es precisamente el de su muerte, ocurrida en Madrid el 28 de enero de 1587 (2).

Si como puede verse la información disponible sobre el protagonista es más bien escueta, todavía más parca es la que se refiere a los antecedentes de la misión que se le encomendó realizar en América lo que, como veremos, es una fuente de problemas para la propia definición de sus objetivos. Se ha aludido con frecuencia al interés personal de Felipe II por los temas relacionados con la naturaleza, la botánica y la farmacopea... se han mencionado incluso algunas propuestas de destacados naturalistas de la época - la del italiano Ulisse Aldrovandi, muy en especial- como posibles antecedentes inspiradores del proyecto,

(2) La mayoría de los datos aquí consignados figuran documentados en la biografía de Somol.inos [2], antes mencionada. Volveremos más tarde a los que se refieren a sus preocupaciones filosófico-morales y algunas de sus amistades. 
pero lo cierto es que nuestra primera información precisa sobre el tema es la propia cédula de instrucciones que Felipe II dio a su protomédico el 11 de enero de 1570 (3). Según esta fuente, muy detallada, el proyecto consistía esencialmente en realizar una "historia de las cosas naturales» de "aquellas tierras" y en primer lugar de Nueva España, «porque se tiene relación que en ella hay más cantidad de plantas y yerbas y otras semillas medicinales conoscidas que en otra parte». Felipe II, rey minucioso además de prudente, en esas instrucciones define incluso la forma precisa en que el protomédico debía llevar a cabo su trabajo:

1. Debía informarse, en todo lugar a donde llegara, por cualquier tipo de entendido («médicos, çurujanos, herbolarios e indios y otras personas curiosas en esta facultad») de «todas las yerbas, árboles y plantas medicinales que hobiere en la provincia donde os halláredes», y hacer una relación por escrito.

$2^{2}$. Debía informarse de "qué experiencia se tiene de las cosas susodichas y del uso y facultad y cantidad que de las dichas medicinas se da", y además "de los lugares adonde nascen y cómo se cultivan... etc.», y recogerlo y anotarlo todo por escrito.

$3^{2}$. Debía procurar experimentar y probar los datos recibidos y, cuando no pudiera, debía informarse de su experimentación por personas fiables y de crédito.

4. "Todas las medicinas o yerbas o simientes» que viera y considerara notables, debía enviarlas a España si allí no las había.

50. La escritura de la Historia, afortunadamente, se dejaba por entero al criterio de Hernández, para que la hiciera "como de vuestro juicio y letras se confía".

69. Por último, cuando terminara su trabajo en Nueva España debía pasar a Perú y realizar la misma tarea.

Pero la misión científica encomendada a Hernández resultaba ser aún más amplia y compleja de lo que esa real cédula, con toda su precisión y detallismo, permite suponer. Así lo demuestra

(3) La mayoría de los documentos conservados sobre la misión de Hernández. en América han sido publicados por José Toribio Medina, Biblioteca HispanoAmericana (1493-1810), tomo II, Santiago de Chile. Fondo Histórico y Bibliográfico José Toribio Medina 1959, págs. 265-297 (reedición facsimilar de la de 1900). La cédula real de instrucciones aparece en las págs. 293-294. 
ya, aunque de forma indirecta, otra cédula real dirigida a los virreyes y demás autoridades coloniales, donde -como de pasada - se dice: "sabed que nos habemos mandado ir a esas partes al doctor Francisco Hernández, nuestro médico, para que haga la historia de las cosas naturales de las nuestras Indias, y porque para dibujar las yerbas y otras cosas naturales y describir la tierra y hacer otras cosas tocantes a lo que se comete terná necesidad de geógrafo y dibujador...) (4). Es decir, desde su mismo principio la misión americana incluía también el hacer una «descripción de la tierra», lo que implicaba la necesidad de que en el grupo investigador hubiera por lo menos otro especialista: un cosmógrafo.

No por casualidad, Hernández llegó a la Nueva España acompañado de su hijo Juan Fernández, que cumplia las funciones de secretario, y además de un cosmógrafo llamado Francisco Domínguez, personaje fundamental cuya labor terminaría siendo paralela a la del propio Hernández, quien se queja numerosas veces de no poder controlarlo. Hay que destacar que esa pequeña comitiva inicial actuó a su vez en suelo americano como centro de un grupo de colaboradores mucho más amplio que incluyó, según la documentación conservada, dibujantes, ayudantes para herborizar y experimentar clínicamente, intérpretes y otras figuras de menos importancia, todos ellos reclutados en el Nuevo Mundo. La misión tuvo así las características de una verdadera expedición científica, la primera de la que tenemos noticias en América, y no fue exclusivamente botánica o naturalista, sino que incluyó también la cosmografía, corografía y hasta las antigüedades - como veremos- de las nuevas tierras.

En este sentido conviene destacar que ese "describir la tierra" y "otras cosas» a las que el rey mismo parece prestar tan poca atención (interesado al parecer especialmente en las "yerbas, árboles y plantas medicinales"), responden sin embargo a un interés estatal y deben inscribirse precisamente en los proyectos de reforma del Consejo de Indias y de la administración americana en general, que tienen como referente destacado a la figura de Juan de Ovando. De hecho, estos aspectos de la misión de Hernández centrados en la descripción cosmográfica de la tierra - con su cartografía - y la historia de las antigüedades indígenas se ajustan literalmente $-y$ es posible que estén vinculados de forma directa - a lo que se establece en las Ordenanzas ovandi-

(4) Instrucciones a los virreyes en apoyo de F. Hernández, datadas el 11 de enero de 1570; las publica Somolinos [2], pág. 152; el subrayado es nuestro. 
nas para el Consejo de Indias, firmadas definitivamente el 24 de septiembre de 1571, Muy en particular están relacionados con la Ordenanza $\mathrm{n}^{\mathbf{9}} 117$, que pide que el cosmógrafo del Consejo «haga y ordene las tablas de la cosmografía de las Indias, asentando en ellas por su longitud y latitud el número de leguas, según arte de geografía, las provincias, mares, islas, ríos y montes y otros lugares....), y con la $n^{0} 119$, que pide además que el mismo cosmógrafo escriba «la historia general de ellas (=las Indias) con la mayor precisión y verdad que ser pueda, de las costumbres, ritos, antigüedades, hechos y acontecimientos, que se entendieren por las descripciones, historias y otras relaciones y averiguaciones que se enviaren a nos en el Consejo" (5).

Todo esto parece indicar que en los orígenes de la misión dirigida por Hernández participaron dos voluntades inspiradoras diferentes. Una, la del propio rey, con un interés prioritario en la botánica y farmacopea; otra, la del reformador del Consejo de Indias, que ponía un énfasis semejante en la necesidad de tener información sobre la cosmografía y las antigüedades de las nuevas tierras. Ambas voluntades eran paralelas y se planteaban como compatibles.

Ahora bien, esa complejísima misión - hacer la historia natural, la descripción de la tierra y el tratado de las antigüedades de México y Perú- se consideraba realizable en los "cinco años primeros siguientes que corran y se cuenten desde el día que os hiciéredes a la vela en los puertos de Sanlúcar de Barrameda o Cádiz» (6). Se trataba, claro está, de un prejuicio (en su más puro sentido etimológico) y siete fueron los años que Hernández tuvo que dedicar finalmente a su misión americana, que además quedó reducida únicamente al territorio de la Nueva España.

Durante ese largo período las ideas del protomédico, director de la empresa en cuanto "trabajo de campo", sufrieron un largo proceso de reacomodación, de cambio profundo. Por la documentación y, sobre todo, por los propios escritos de Hernández podemos ver cómo fue planteándose así una tercera voluntad rectora para el proyecto, fenómeno que por supuesto vino a complicar todavía más su ejecución.

(5) Marcos JIMÉNEz DE LA EsPADA: Relaciones geográficas de Indias, col. BAE, n² CLXXXIII, vol. I, Madrid. ed. Atlas, 1965. pág. 45.

(6) Titulo de Protomédico, párrafo 3, en Somolinos [2], pág. 154. 


\section{EL PROCESO DE EJECUCIÓN: REALIZACIÓN Y CONFLICTO}

La documentación conservada permite reconstruir con bastante detalle el proceso material de realización del «trabajo de campo" dirigido por Hernández y, de hecho, Germán Somolinos ha dedicado mucha atención a este punto en su monografía clásica antes citada. Nuestro objetivo aquí se reduce únicamente al proceso «intelectual» de realización de la empresa, destacando sobre todo la forma en que se manifiestan o se confrontan las diferentes voluntades que la inspiraban. Por desgracia, para ello disponemos únicamente de la documentación generada por uno de los personajes, las 18 cartas escritas durante este período por el propio Hernández (7).

A partir de ese epistolario sabemos que inicialmente el protomédico parece no sólo haber asumido el proyecto real, haciéndolo suyo en su integridad, sino que hasta había decidido ampliarlo geográficamente aún más: «es menester para la perfección desta obra que V.M. mande escribir a las islas de Canarias, Santo Domingo y China hagan lo que yo les ordenare, y será que envien pinturas en pequeño de todo lo natural, que podrán hacer fácilmente, con relación de los indios y españoles, de sus virtudes y provechos, para que yo lo haga acá pintar a mi modo y ponga en estilo...» (8). Aunque Hernández percibe que el proyecto así planteado no es abarcable, cree que merece la pena intentarlo: "aunque ninguno pueda comenzar y acabar, hará V.M. un principio de que se admire el mundon (9).

Estos textos son de diciembre de 1572 y el protomédico, a pesar de los problemas con que ya se había encontrado, estaba lleno de ilusión. Hernández había llegado a México en febrero de 1571 y por mayo de ese mismo año aún estaba realizando los preparativos para iniciar su obra (10). En abril de 1572, cuando dice de su trabajo que "habrá un año que lo comencé», ya había tomado el pulso a su empresa; asombrado de la riqueza botánica de México, cree firmemente que Nueva España puede proveer

(7) Las 18 cartas del epistolario, tres dirigidas a Ovando y todas las restantes al Rey, están datadas entre 1571 y 1576 . Casi todas ellas, completadas además con otros documentos, fueron publicadas por José Toribio MEDINA [4], págs. 272 292. Dos nuevas cartas al Rey, y otras cinco cartas ya publicadas por Medina, lueron editadas por José Luis BenítF. MIURA, "El Dr. Francisco Hernandez: 15141578 (cartas inéditas)", Anuario de Estudios Americanos, t. VII, 1950, págs. 367 409.

(8) Carta al Rey, 12 diciembre 1572; Medina [4], pág. 275.

(9) Ibidem.

(10) Clr. carta al Rey, 15 de mayo de 1571; Benítez Miura [8], págs. 396-397. 
de medicamentos a todo el mundo y por ello ha decido escribir su obra «en latín para que se comunique la merced que V.M. hace al mundo a todas las naciones por esta lengua que es más común", aunque añade "y también se escribe en romance para otros, porque todos lo gocen"; pero al mismo tiempo se da cuenta ya de la inmensidad del trabajo: "yo truxe de término cinco años; es necesario V.M. le mande prorrogar hasta nueve o diez..." (11)

Según el epistolario, hasta este punto el protomédico sigue con una fidelidad absoluta el proyecto rector definido por el monarca; expresión escrita de fidelidad que parece culminar en una carta de marzo de 1573. En ella no sólo se insiste en los puntos anteriores y en los aspectos botánicos y de farmacopea, sino que se llega incluso a describir el método que Hernández sigue en su trabajo de campo, destacándose con verdadera minucia la escrupulosa aplicación que se hace de las instrucciones recibidas del propio Rey (12).

Ahora bien, todo este cuadro se altera con sorprendente brusquedad con el contenido de las tres únicas cartas conocidas, datadas entre septiembre de 1574 y marzo de 1575, de las que el protomédico dirigió a Juan de Ovando, presidente del Consejo de Indias. Por la primera de ellas (13), en la que es manifiesto que existieron otras anteriores, nos enteramos - por primera vez en la documentación conservada- de que Hernández ha terminado ya "una historia de las antigüedades desta tierra, que a contemplación de vuestra señoría illustrísima se ha compueston; que además tiene muy avanzadas y va a enviarle "las graduaciones hechas (de la cosmografía)»; y, por último, que «el Plinio, ansímismo, está acabado de trasladar en lengua española y por la mayor parte illustrado". Estas declaraciones confirman que fue Juan de Ovando quien había encargado a Hernández la tarea de medir la tierra - la cosmografía - y que también fue él quien le había solicitado la realización de las antigüedades; por eso es a Ovando - y no al rey - a quien comunica y envía los resultados de las mediciones y por eso dice, todavía más explícitamente, haber escrito las antigüedades «a contemplación de vuestra señoría illustrísima». Aparece aquí claramente definida la segunda voluntad rectora del proyecto.

Pero hay algo más, por el tono general con el que el protomé-

(11) Todas las referencias en carta al Rey, 30 de abril de 1572; MEdina [4], págs. 272-273.

(12) Carta al Rey, 31 de marzo de 1573; Medina [4], págs. 275-278.

(13) Carta a Ovando, 1 de septiembre de 1574; MEdina [4], págs. 280-281. 
dico se dirige al presidente del Consejo de Indias se diría que le conoce personalmente 0 , al menos, que aprecia en él muy especialmente la preocupación por las letras. En ese contexto se inscriben precisamente los comentarios sobre su tarea como traductor y comentarista de la obra de Plinio. Más aún, también en ese contexto se inscribe otra información de notable interés porque reafirma el que Hernández no está dedicado únicamente a escribir sus libros de plantas y animales con fines sobre todo médicos, objetivo prioritario definido por el Rey, Hernández comunica al Presidente del Consejo de Indias que ya tiene diseñada una "tabla y antidotario de las cosas desta tierra", obra que si ha tenido que ser planeada y se ha vuelto necesaria es porque el protomédico ha tenido que descartar para su obra principal -la «Historia Natural de la Nueva España»_ el modelo clásico previsible para una obra orientada esencialmente a la farmacopea, Dioscórides. Evidentemente el protomédico tenía ya en mente una obra mucho más amplia, cuyo modelo probablemente era el de Plinio, pero lo que parece sorprendente es que todo esto lo comunique a Ovando y no al Rey, y además que sea precisamente a Ovando a quien diga que no sólo la escribe en latín y la traduce al castellano, sino también «en lengua mexicana para utilidad de los naturales». Hernández, con todas estas declaraciones dirigidas a un interlocutor muy especial, está expresando ahora sus propias ideas, su propia voluntad con respecto al proyecto.

En la conformación y definición de esa tercera voluntad rectora ha intervenido un acontecimiento muy importante. Justo después de aquella carta dirigida al monarca de abril de 1573, en la que Hernández expresaba su plena adhesión al proyecto real, el protomédico salió de la capital mexicana para realizar su gran viaje de exploración, experiencia decisiva que no concluyó hasta principios de marzo de 1574 (14). En las sucesivas cartas que Hernández dirigió al monarca durante este período sus comunicaciones son escuetas; no se expresa una alteración de planes, pero constantemente se destaca la enorme riqueza y abundancia de los materiales encontrados. Sin embargo, en la última de las cartas de esa serie, escrita el 31 de marzo de 1574, aparece un indicio muy importante de lo que estaba ocurriendo en la mente del protomédico. Hernández, apenas vuelto del viaje y ensalzando

(14) Véanse las cartas dirigidas al Rey del 31 de marzo y del 10 de septiembre de 1573, la del 31 de marzo de 1574 y la que está sin datar, pero que corresponde a abril de 1573; MEDiNa [4], págs. 274-280 y págs. 289-292 (para la sin datar). 
la enormidad de su propio trabajo, dice haber relizado ya «dos volúmines de escriptura, en que se contienen veinte y cuatro libros, todos de cosas nuevas y de grande provecho, de ninguno hasta agora escriptas ni averiguadas»; de forma muy significativa, agrega a continuación que no «como Dioscórides, [que aún con la ayuda de los que le precedieron no había escrito de todo esotro orbe más que seis» (15). En resumen, esta referencia indica que la estructura definitiva de la «Historia Natural de la Nueva España» (o al menos la referente a la "Historia de las Plantas») estaba ya fijada, aunque el Rey no lo supiera, y que el modelo clásico de Dioscórides no era precisamente el que más gustaba a Hernández. A continuación de esto tiene lugar la carta dirigida a Juan de Ovando, de septiembre de 1574, que antes hemos abordado.

No podemos seguir aquí, en todo su detalle y consecuencias, el proceso que venimos comentando. Como ejemplo ilustrativo de la forma en que esas tres voluntades rectoras se relacionaban conviene mencionar dos cartas que Hernández dirige al Rey y al presidente del Consejo de Indias datadas con la misma fecha, el 1 de diciembre de 1574. La carta dirigida a Juan de Ovando (16) es prácticamente una repetición de la que antes hemos comentado, salvo que su parte nuclear es una solicitud de dinero. La que dirige al Rey (17) es significativamente diferente: agradece mercedes (aunque no las ha podido hacer efectivas, origen de sus problemas económicos) y describe su trabajo, en el que sólo se mencionan libros de plantas y farmacopea; informa además que está centrado en sus experimentaciones clínicas y que va a hacer un «libro de sustitutos» de medicinas europeas por medicinas americanas con el fin de abaratar los fármacos en México. Claramente, cuando escribe al Rey, Hernández sigue siendo el autor de una obra esencialmente médica y próxima a la de Dioscórides.

El gran cambio en ese extraño juego de equilibrios se produjo a raíz de que el protomédico se enteró de la muerte de Ovando, ocurrida el 8 de septiembre de 1575. En la carta del 10 de febrero de 1576 (18) el naturalista, por primera vez, informa al Rey con detalle de todas las obras que está realizando y de las verdaderas dimensiones de su empresa. En primer lugar están, por supuesto, «los libros de plantas, animales y minerales desta 279.

(15) Todas las citas en carta al Rey, 31 de marzo de 1574; MEdina [4], pág.

(16) Carta a Juan de Ovando, 1 de diciembre de 1574; Medina [4], pág. 281.

(17) Carta al Rey, 1 de diciembre de 1574; Medina [4], págs. 281-282.

(18) Carta al Rey, 10 de febrero de 1576; Medina [4], págs. 284-285. 
tierra", que aún define en términos médicos como "de muy grande utilidad ansí para la salud de todos como grande excusa de gastos en medicinas»; pero luego advierte que para que cumplan esas funciones es preciso completarlos con "otros cuatro libros muy necesarios a la perfección de la Historia Natural, los cuales están ya acabados en borrador, que son: "Método de conoscer las plantas de ambos orbes", "Tabla de los males y remedios desta tierra", "Las plantas dese orbe que nacen en este y los provechos que tienen entre los naturales" y el de las "Experiencias y antidotario" deste». En segundo lugar informa al Rey de la existencia de "los treinta y siete libros de Plinio acabados de traducir y comentar». En tercer lugar hace una rapidísima mención de la "historia desta tierra», de la que dice "no estar del todo acabada", pero que cree "dará gusto a V.M. cuando yo vaya y la lleve». Por último, el trabajo cosmográfico es mencionado aún más sobre ascuas, sin comentario alguno y casi como una referencia casual: "cuando yo vaya llevaré (quedando acá esquizos y traslado de todo) la historia y chorografia desta tierra..."

Teniendo al Rey como interlocutor, la jerarquización de los materiales está clarísima y en ella me parece importante destacar el proceso de reacomodación -y reelaboración- que reflejan esas menciones a las antigüedades y al trabajo cosmográfico. Pero hay más, Hernández se disculpa de no poder ir al Perú, alegando razones de salud y de edad, pero poniendo también énfasis en otro motivo más intrigante: "la grande necesidad que hay de mi en esa tierra [España], ansí para la impresión, sin la cual se perdería todo, como para otras cosas que tocan al servicio de S.M.».

Sobre esta última cuestión nos da mayor información la última carta conservada, dirigida al Rey el 24 de marzo de 1576 (19), tan sólo un mes más tarde que la anterior. Hernández ha recibido orden fulminante e inapelable de enviar todo su trabajo al monarca y al hacerlo, un tanto resignado, comenta que sus «diez y seis libros grandes de la historia natural desta tierra»: "no van tan limpios ni tan limados o tan por orden (ni ha sido posible) que no deban esperar la última mano antes que se impriman». Explica que las figuras van en limpio, pero mezcladas, según el orden en que se fueron acabando; el texto, sujeto a correcciones, va por su parte para no estropear los dibujos con las inevitables enmiendas; hay repeticiones, por descuido o por deseo de mejora... Todo debe organizarse unitariamente y «terná en la impresión

(19) Carta al Rey, 24 de marzo de 1576; MEdina [4], págs. 285-287. 
fácil remedio», mientras tanto sólo hay una tabla de correspondencias entre dibujos y textos que, por cierto, me hace pensar en el modelo impuesto por la obra anatómica de Andrea Vesalio.

Por supuesto, después viene la enumeración de todas las otras obras ya mencionadas en la carta anterior, incluyendo el Plinio y agregando de coletilla uotras cosas de philosophia y medicina conque sé recibirá V.M. gusto y servicio». Finalmente reitera su disculpa de no ir al Perú por motivos de salud e insiste una vez más en que «mi presencia y vida será allá necesaria para la perfectión, impresión y uso de mis libros y otras cosas que tocan al servicio de V.M.».

A mi entender, detrás de todo esto había un motivo no expreso. Hernández procuraba mantener su papel rector dentro del proyecto ofreciendo una obra prácticamente terminada y muy bien pensada, pero en la forma de un manuscrito incoherente compuesto de notas y libros, más o menos en limpio, unido a otro conjunto de dibujos revueltos. Todo debía organizarse según un plan que sólo el protomédico conocía y mantenía en su cabeza, pero que en ningún momento parece haber comunicado al Rey o haberlo declarado por escrito. Más aún, por la documentación conservada, Hernández deja bien claro que ese plan únicamente se plasmaría en la «impresión, sin la cual se perdería todo». Por eso precisamente dice también que su presencia era imprescindible "para la perfección, impresión y uso de mis libros». Para nuestra desgracia, si esa fue la idea, fracasó por completo y la obra se resintió muchísimo de ello.

3. EL PROYECTO HERNANDIANO: LOS PROBLEMAS DE ESTUDIAR UNA OBRA ABIERTA Y EL MODELO DE PLINIO

El proceso que acabamos de reseñar no culminó con la confección de un escrito final, acabado y coherente, realizado por Hernández. Como es bien sabido, al monarca le placieron sobremanera los materiales recibidos y los guardó "en su guarda joyas» como cosa propia (20); más aún, decidió incluso que era necesaria su publicación, pero para ello era imprescindible organizar y hacer manejable aquella masa ingente de escritos y ma-

(20) La mención aparece en el testamento de Hernández del 8 de mayo de 1578, publicado por Agustín Jesús BarReIro MARTínez, "El testamento del doctor Francisco Hernández.", Boletín de la Real Academia de Historia, $\mathrm{n}^{Q}$ XCIV, 1929, págs. 475-497; la cita aparece en la pág. 493. 
teriales. De esta forma, la obra pasó en 1580 -todavía en vida del autor- a otras manos que, según criterios que se consideraron los prioritarios o más convenientes, la modelaron, resumieron, organizaron y así, finalmente, salieron publicados y se dieron a conocer. Este proceso de remodelación y reelaboración no ocurrió una sola vez, sino que a lo largo de los siglos se llegó a producir al menos en tres ocasiones. No es éste lugar para entrar en la larga y compleja historia de los manuscritos y ediciones relacionados con la obra de Hernández; el interesado puede encontrarla, aunque necesitada de actualización y revisión, en el trabajo tantas veces citado de Germán Somolinos.

Lo que nos importa destacar es que, como consecuencia de esos abatares sufridos por los manuscritos (divididos al menos en dos familias, la que tenía el Rey en su biblioteca y la que conservó y siguió anotando el propio Hernández) y como consecuencia también de cuatro siglos de ediciones parciales (que afectan a las dos familias principales de manuscritos), la obra de Hernández ha llegado a nosotros en la forma de un conjunto monumental de escritos autógrafos - poco estudiados y en buena parte aún inéditos- que debe completarse con otro conjunto no menos monumental de escritos impresos, en los que es muy difícil saber que se debe a Hernández y qué a sus editores. El estudio y la comprensión del proyecto de Hernández y de su obra propiamente dicha plantean así unas dificultades poco comunes y exigen un cuidado crítico extremo.

Esto no se ha subsanado tras el formidable esfuerzo de divulgación y publicación de materiales inéditos que representó la edición de las llamadas Obras Completas de Francisco Hernández por la Universidad Nacional Autónoma de México (21). Se trata sin duda de una edición importantísima, pero tiene como limitación el no ser verdaderamente completa ni crítica.

Con respecto a la "Historia Natural de Nueva España" por ejemplo, esta edición se limita a traducir del latín la edición del siglo XVIII - preparada por Casimiro Gómez Ortega - para los libros referentes a las plantas y la del siglo XVII — preparada por

(21) Francisco HeRnández: Obras Completas, 7 vols. en 8 tomos, UNAM, México, 1959-85. La serie está compuesta de los siguientes volúmenes: I. Vida y obra de Francisco Hernández, por Germán Somolınos D’ARDoIs, México, 1960; If, y III. Historia Natural de Nueva España, México, 1959; IV y V. Historia Natural de Cayo Plinio Segundo, Mexico, 1966 y 1976, parte completada con un vol. V. bis. México, 1976 con la traducción de los libros faltantes publicada por Gerónimo de la Huerta en 1624; VI. Escritos varios, México, 1984; y VII, Comentarios a la obra de Francisco Hernández, por los miembros de la Comisión Francisco Hernández, México, 1985. 
la Academia de los Lincei-para la de los animales y minerales. Se ha renunciado así a confrontar esos textos con los manuscritos conocidos del propio Hernández que sobre estas mismas obras existen en Madrid, originales que por cierto reflejan claras variantes e incluyen otros materiales ausentes en la edición (22).

Por otra parte, el lógico interés por las aportaciones de Hernández como naturalista ha llevado a que en esta publicación de las Obras Completas se de un tratamiento secundario a los escritos de carácter filosófico, moral y religioso, escritos y traducciones que sin embargo son decisivos para entender no sólo el pensamiento del protomédico, sino su propia actividad como naturalista. Con respecto a este tipo «secundario» de obras, la edición no sólo acusa problemas críticos sino que además tiene una ausencia destacadísima, pues ni siquiera menciona la existencia de la que probablemente es su realización más importante en este campo: «Las Obras del bien auenturado Sanct Dionissio Areopagita, traduzidas por el Doctor Francisco Hernández, médico e historiador de Philippo Segundo y su protomédico general en todas las Yndias Occidentales» (23).

No se trata de un escrito cualquiera, sino de la única versión completa conocida en castellano de las obras de esta gran autoridad, inspiradora y amparadora de buena parte de la espiritualidad española de los siglos XVI y XVII (24). Hernández traduce y adapta al castellano "Las Epístolas», el "Libro de la Theología Mística" y el "Libro de los nombres diuinos", obra esta última que inspiró a su ilustre coetáneo Fray Luis de León. Cerrando el volumen, a estas tres obras sigue otra de no menor influencia, el "Libro de las Celestial Hierarchía» y su inevitable complemento, el "Libro de la Eclesástica Hierarchía», un tratado particularmente problemático y delicado para el momento en que Hernández hizo su adaptación. Debe señalarse que los contenidos de estas traducciones de San Dionisio -o Pseudo-Dionisio Areopagita,

(22) En otro lugar abordaremos el tema del número total de manuscritos que sobre esta obra se conservan actualmente en Madrid. Podemos anticipar que han reaparecido todos los autógrafos utilizados por Casimiro Gómez Ortega en su edición, una parte importante de los cuales se había dado por perdida.

(23) Se trata de un manuscrito autógrafo en folio, encuadernado en pergamino, con un total de $100 \mathrm{ff}$. El manuscrito se guarda en la Biblioteca Nacional de Madrid, procede de la Colección Osuna, y tiene la signatura de Ms. 10.813. Cabe agregar que se trata de una copia final, en limpio, tan cuidada que parece preparada para la imprenta.

(24) Véanse los comentarios de Elogio PACHO, "Versiones castellanas de Pseudo Dionisio Areopagita". Revista Española de Teología, n 30, 1970, págs. 245 264. Hasta donde conozco este autor es el primero en mencionar la existencia de esta traducción de Hernández, cfr. págs. 249-251. 
para ser más exactos- se encuentran muy próximos, en forma y fondo, a los "Christianae Methodi libri tres", una de las obras más intrigantes del protomédico, escrita —según él mismo dicepor encargo de su «íntimo amigo» el arzobispo de México Pedro Moya Contreras, personaje que además anotó y comentó parcialmente su contenido en una columna paralela dispuesta al efecto en el manuscrito conservado (25).

Obras como estas últimas, unidas a otras como sus intentos de adaptación ecléctica de la teoría aristotélica con la estoica, son muestra clara de la complejidad del pensamiento de Hernández, complejidad que de forma indudable caracterizaba también a su proyecto como naturalista. Pero las características intelectuales de ese proyecto es precisamente aquello que se ha vuelto más difícil de entender y estudiar, porque la desafortunada suerte editorial de los manuscritos ha hecho que Hernández parezca esencialmente como un formidable herborizador y colector de datos.

El protomédico tenía sin embargo una idea muy precisa sobre su obra naturalista y lo que representaba. Por ejemplo, después de describir un hermoso árbol llamado quauhxóchith dice: "carece de sabor $\mathrm{y}$ olor notables, y nada digno de mención he sabido acerca de él. Lo describimos sin embargo por su extraordinaria figura y hermoso aspecto, como hemos hecho con otros muchos, porque no es nuestro propósito dar cuenta sólo de los medicamentos, sino reseñar la flora y componer la historia de las cosas naturales del Nuevo Mundo, poniendo ante los ojos de nuestros contemporáneos, y principalmente de nuestro señor Felipe, todo lo que se produce en esta Nueva España» (26). Si esta declaración no deja dudas sobre su intención de componer una auténtica y completa "Historia de las cosas naturales del Nuevo Mundo", en otro texto posterior - el memorial dirigido al Rey, datable entre finales de 1577 y principios de 1578- dice que lo que ha hecho en América es lo siguiente:

10. «Pintar y describir las cosas naturales de aquella tierra [=la Nueva España] lo mejor y con más verdad que le ha sido posible",

(25) La obra ocupa los if. 58-86 del volumen conservado en la Biblioteca del Ministerio de Hacienda de Madrid con la signatura 931. Una traducción al castellano de esta obra ha sido publicada en las Obras Completas [22], vol. VI, págs. 427-472.

(26) Hernández. [22], vol. III, pág. 116; el subrayado es nuestro. 
29. "Y hacerla medir en longitud y latitud por el cielo",

39. "Y escribir la historia de las regiones occidentales con sus repúblicas y costumbres, dibujos de dioses, de sacrificios y otras antigüedades» (27).

Estas tres actividades básicas, que ya nos eran bien conocidas, en esta ocasión son presentadas implícitamente por Hernández como las partes constitutivas de una sola obra, la mismísima «Historia Natural de Nueva España», porque inmediatamente a continuación de su enumeración dice: "Y porque la historia natural deste orbe se juntase con la del otro, trae acabados de traducir y comentar los treinta y siete libros de la Historia Natural de Plinio.... (28).

Es decir, la "descripción de las cosas naturales», la descripción cosmográfica y la de las antigüedades se habían transformado finalmente para el protomédico en las tres partes que componían su proyectada "historia natural deste orbe». Obra que así entendida no dudaba en contraponer -como su complemento imprescindible- a la "Historia Natural de Plinio", o sea la que era considerada como la historia natural modélica del Viejo Mundo.

En relación con la importancia que este modelo clásico parece haber tenido en la estructuración del proyecto hernandiano para su «Historia Natural de Nueva España», es significativo señalar que los 37 libros de la obra de Plinio -ésos que Hernández mismo había traducido e «illustrado" (en el sentido de comentado) - se organizan genéricamente en los siguientes núcleos temáticos:

Libro I.

Libro II.

Libros III-VI.

Libro VII.

Libros VIII-XI.
Dedicatorias, sumario de todos los libros, listas de los autores citados.

Cosmología ( Del mundo, elementos y estrellas").

Cosmografía (descripción de Europa, Africa y Asia).

«Del hombre y de las cosas que han sido por él halladas».

Zoología (animales terrestres, acuátiles, aves e insectos).

(27) Memorial al Rey, sin fecha, datable entre finales de 1577 y principios de 1578; Medina [4], págs. 292-293; citas en pág. 292.

(28) Ibidem. 
Libros XII-XIX. Libros XX-XXXII.

Libros XXXIII-XXXVII. Metales, pigmentos y piedras (gemas).
Botánica (clasificación compleja).

Medicina (concepto muy amplio, que incluye alimentación, farmacopea, etc.).

En la obra de Plinio, no por casualidad, encontramos en primer lugar el núcleo que Hernández suele denominar "Chorografían: el cielo y la tierra, seguidos de la descripción de la superficie terrestre o geografía (tanto física como humana). En segundo lugar, el historiador romano afronta lo que Hernández suele sintetizar cómo "Antigüedades»: el Hombre y sus realizaciones; conjunto que aparece en Plinio como pórtico privilegiado con el que se inicia la exposición de las cosas naturales individualizadas, es decir de todo aquello que habita o está sobre la tierra. En tercer y último lugar la obra pliniana presenta la descripción de las cosas naturales propiamente dichas: animales, plantas, minerales, pigmentos y piedras, acompañados de un importantísimo conjunto dedicado a cosas de interés médico en un sentido muy amplio. Este tercer núcleo corresponde sin duda a los libros con las descripciones de animales, plantas y minerales realizados por Hernández, pero también a este núcleo inspirador deben corresponder esos otros libros de carácter médico realizado por el protomédico y a los que él llama "adminiculativos» y describe, en relación con los anteriores, como "muy necesarios» y «que servirán para su uso».

En resumen, toda la gigantesca obra naturalista realizada por Hernández en Nueva España parece integrarse en un solo proyecto global que cobra sentido a la luz del modelo clásico de Plinio. Sabemos también, por lo conservado, que el protomédico introdujo correcciones y modificaciones a ese modelo (ya lo hizo en la propia traducción que fue completando, precisamente, a medida que iba avanzando su tarea en Nueva España), pero la profundidad y el significado de esas alteraciones no pueden ser evaluados por ahora. Del gran proyecto de Hernández hemos perdido por completo toda la sección "chorográfica» $\mathrm{y}$, además, todos los libros «adminiculativos». Por otra parte, un estudio en esta línea de lo que hemos conservado de la descripción de las "cosas naturales» depende, en buena medida, de su previa fijación crítica. Sólo las "Antigüedades» se presentan por el momento como el conjunto adecuado para ensayar una primera contrastación sobre lo que aquí hemos venido diciendo. 
4. EL HOMBRE AMERICANO: LAS ANTIGÜEDADES COMO UN MODELO DE LA EVOLUCIÓN SEGUIDA POR EL PENSAMIENTO DE HERNÁNDEZ Y DE SU COMPLEJIDAD

Una aproximación sin excesivo detalle a esta obra (29) pone ya de manifiesto que en ella hay varias fases de elaboración, la última de las cuales no llegó a terminarse, por lo que el conjunto no está completamente ordenado ni integrado. Parece, por tanto, que ésta fue una deficiencia común a todo los componentes del proyecto diseñado por Hernández. Ahora bien, en el caso concreto de las Antigüedades este hecho va unido a una serie de interesantes contradicciones que aparecen su alrededor y que permiten precisar algunas cuestiones de importancia sobre la obra.

En realidad, las contradicciones comienzan por la propia definición de los fines que originaron su realización. Como ya hemos visto con anterioridad, el protomédico dice explícitamente en las cartas dirigidas en 1574 a Juan de Ovando que ha escrito tal obra "a contemplación de vuestra señoría illustrísima» (30). Es decir, que la ha hecho a solicitud de Ovando y probablemente dentro del mismo contexto que dio origen a las ordenanzas ovandinas para el Consejo de Indias.

No obstante, pocos años más tarde (c. 1576), en el "proemio» que finalmente antepuso a la obra para dedicarla a Felipe II, Hernández emplea una argumentación completamente diferente. De forma inesperada, el protomédico comienza ese "proemio» por lo que es una auténtica disculpa ante el Rey por haber escrito una obra con esa temática $y$, para justificarse, recurre a una razón de orden lógico-profesional, la extensión de su actividad como naturalista al hombre americano y sus costumbres: "Aún cuando me hayas comisionado tan sólo para la historia de las cosas naturales deste orbe, Sacratísimo Rey, y aunque el

(29) El manuscrito autógrafo de las Antigüedades se conserva en la Real Academia de la Historia de Madrid y su texto ha sido publicado en tres ocasiones. Primero, en edición fototípica a cargo de Francisco del Paso y Troncoso, con el título: De Antiquitatibus Novae Hispaniae, México, Museo Nacional de Arqueología, Historia y Etnografía, 1926. La segunda edición es la traducción al castellano realizada por Joaquín García Pimentel, publicada póstumamente y aparecida con el título: Antigüedades de la Nueva España, México, Pedro Robredo, 1945. La tercera y última es la reedición de la traducción antes citada dentro de las Obras Completas [22], vol. VI, págs. 45-197. En las referencias utilizaré la edición de 1945.

(30) Carta a Ovando, 1 de septiembre de 1574; Medina 44], pág. 280. La referencia se repite casi idéntica en la carta a Ovando del 1 de septiembre de 1574: "un libro de las antigüedades desta gente que se ha hecho a contemplación de vuestra señoría ilustrísima"; MEDina [4], pág. 281. 
cargo de escribir sobre antigüedades, pueda considerarse como que no me pertenece, sin embargo, juzgo que no distan tanto de ella las costumbres y ritos de las gentes...» (31).

Más tarde volveremos sobre este importante razonamiento del protomédico que hemos dejado trunco, ahora lo que nos interesa destacar es que si la obra fue hecha porque la solicitaba Ovando, en fechas anteriores a 1574 y en relación con su política y cargo, no pudo tener como origen una necesidad lógica sentida por Hernández de incluir al hombre americano entre sus objetivos de estudio como naturalista. Esta segunda justificación, que sin embargo es coherente con el desarrollo que alcanzó finalmente el proyecto del protomédico, la encontramos sólo en textos dirigidos a Felipe II y posteriores a la muerte de Ovando en 1575. Lo sorprendente es que entonces hay también una omisión sistemática de toda referencia al ya difunto presidente del Consejo de Indias, es decir de la persona a cuya "contemplación» se había hecho en origen la obra.

Estas argumentaciones tan distintas -sobre las que evidentemente está actuando una importante diferencia de tiempo e interlocutor - están en clara relación con otra serie de declaraciones que se refieren al proceso mismo de ejecución de la obra. Por una parte, en las cartas que Hernández dirigió a Ovando en septiembre y diciembre de 1574 (32), el protomédico presenta las Antigüedades como una obra que ya se "ha escrito", que ya "se ha hecho»... Sin embargo, en la carta que dirigió al Rey en febrero de 1576, Hernández dice con respecto a la misma obra "no estar del todo acabada» (33). A su vez, en el "proemio» (de finales de 1576) realizado cuando Hernández había renunciado ya a seguir retocando su escrito, el protomédico presenta finalmente su obra como algo provisional e inacabado: "una fábrica que tal vez dilataré y aumentaré en los dias futuros» (34).

En otras palabras, este conjunto de referencias aportadas por el propío Hernández permiten reconstruir el proceso de ejecución de la obra en la siguiente forma. Hacia finales de 1574 se había terminado una primera versión de las Antigüedades, versión cuyo destinatario era Juan de Ovando. Para principios de 1576, sin embargo, la obra había entrado en un nuevo proceso de elabora-

(31) Hernánitez., Antigüécdudés [30], pág. 11.

(32) Cartas a Ovando del 1 de septiembre y del 1 de diciembre de 1574; Medins [4], págs. 280-81 y 281.

(33) Carta al Rey, 10 de febrero de 1576; Medina [4], pág. 284.

(34) Hernáninez, Antigüedades [30], pág. 12. 
ción que sólo se dió por terminado - aunque se dice que provisionalmente - hacia finales de ese mismo año, cuando Hernández dedicó el- manuscrito a Felipe II. Es evidente que ambas fases de elaboración están separadas por la muerte -el 8 de septiembre de 1575- de Juan de Ovando.

El proceso de ejecución que se deduce de los testimonios anteriores queda corroborado plenamente por el análisis crítico del manuscrito conservado. Todas las referencias cronológicas que aparecen en la obra hacen siempre mención a las fechas de 1573 y 1574. Por ejemplo, en el Libro II, cap. 19, se dice: «desde ese tiempo hasta el año de 1574 su postrero sol había cumplido 880 [años]" (35); o bien, ahora con una referencia cronológica de carácter indirecto, en el Libro II, cap. 13, se dice: "quedan todavía dos palacios reales [de Nezahualpilli en Texcoco], uno donde hoy está el convento y el otro donde dictamos esto..." (36). Referencia esta última que permite precisar que la redacción de la obra se hizo, al menos parcialmente, durante el viaje que el protomédico realizó en torno a la ciudad de México entre finales de abril de 1573 y principios de 1574» (37).

Estas referencias cronológicas concretas aparecen en lo que podemos llamar el texto "primitivo" de las Antigüedades, cuya estructura y características son perfectamente reconocibles aún hoy y sobre el que volveremos después. Ahora lo que nos interesa destacar es que, con esa versión escrita entre 1573 y 1574 como base, Hernández introdujo una larguísima serie de correcciones y nuevos textos que cambiaron la organización original de la obra, haciéndola mucho más confusa y dándole el aspecto inacabado con el que hoy se nos presenta. Aunque esos textos nuevos que se fueron introduciendo no están datados, como tienen por efecto alterar y complicar la organización del escrito realizado en 1573-74, deben corresponder necesariamente a un proceso de elaboración posterior a esa fecha. Es decir, la versión que según el epistolario fue realizada "a contemplación» de Ovando y estaba terminada en 1574, corresponde claramente al texto "primitivo" escrito entre 1573 y 1574. La reelaboración de la obra que - según comunica Hernández al Rey- se estaba llevando a cabo a lo largo del año de 1576, debe corresponder a la fase en que se introducen los textos nuevos.

(35) Idem, pág. 130.

(36) Idem, pág. 115.

(37) Cfr. las cartas al Rey datadas entre el 31 de abril de 1573 y el 31 de marzo de 1574; MEDINA [4], págs. 275-279 y 289-292. 
El protomédico, por tanto, remodeló efectivamente su obra sobre las antigüedades mexicanas $\mathrm{y}$, por convicción o por necesidad, esa segunda fase de elaboración corresponde precisamente al momento en que Hernández hizo el esfuerzo más sistemático por integrar este escrito como una parte más de su gran proyecto naturalista. Es importante, por tanto, intentar precisar cómo se produjo esa remodelación y sobre qué base textual previa se hizo.

Propiamente el estudio de estas cuestiones exige un análisis crítico completo del manuscrito conservado que, aunque ha sido realizado, no puede incluirse aquí por razones lógicas de espacio. En el apéndice de este trabajo el lector puede encontrar, a modo de compensación y guía básica, una tabla en la que se recoge de una forma simplificada la estructura de contenidos de la obra y las fuentes utilizadas por Hernández. Ahora me limitaré a sintetizar y exponer algunas de las conclusiones más importantes que se pueden extraer de ese análisis.

Hernández estructuró originalmente su trabajo — versión terminada en 1574- como tres libros con 20 capítulos cada uno. A esa estructura básica le fue agregando después los nuevos textos, algunos personales y la mayoría sacados de la obra de Sahagún. Como se ha dicho anteriormente, esos nuevos materiales fueron siendo interados a la estructura de capítulos fijada en 1574, sustituyendo materiales o ampliando los ya existentes, lo que introdujo inevitablemente distorsiones y modificaciones en la propia idea rectora que articulaba el conjunto y daba sentido a sus partes.

De esta forma, el Libro I, que es único en el que la importancia y extensión del material agregado llegó a alterar hasta el número de capítulos (de los 20 originales a los 28 actuales), tiene hoy una coherencia y sucesión lógica tan laxa que incluso hace difícil resumir su temática en un solo término o concepto. Empieza con la descripción geográfica de todas las Indias y termina con la descripción de la ciudad de México, del físico de los indígenas y de sus mercaderias (especialmente de las que «no tenían"). Entre esos extremos se desarrolla lo que un antropólogo moderno llamaría el "ciclo vital», pero bastante entrelazado en su exposición con cuestiones propias de la estructura social y política.

La historia interna de este primer libro explica en buena medida esa aparente desorganización. Originalmente Hernández había escrito este libro basándose por completo en los materiales 
extraídos de la obra de Francisco López de Gómara, Historia de las Indias y Conquista de México (38), impresa en Zaragoza en 1552 (39), de la que por cierto aprovecha sobre todo el apéndice etnográfico que aparece al final de la Conquista de México. Ese texto básico lo corrigió y amplió después con nuevos datos, algunos obtenidos de forma personal y la mayoría sacados de la Historia Universal de las cosas de la Nueva España de fray Bernardino de Sahagún (40). Cabe agregar además que esos préstamos fueron tomados directamente de la versión en náhuatl de la obra del franciscano, cuestión que no sólo demuestra con claridad el análisis crítico (41), sino que además se reafirma por el hecho de que la gran mayoría de los materiales han sido tomados del Libro VI de la Historia Universal y ese libro precisamente tiene un colofón que data su traducción al castellano en el año 1577 (42), es decir cuando Hernández había terminado ya de elaborar sus Antigüedades.

(38) La obra, impresa por primera vez en Zaragoza 1552, tuvo un éxito editorial notable. Volvió a publicarse dos veces en 1553 (una en Zaragoza y otra en Medina del Campo) y tres veces en 1554 (una en Zaragoza y dos en Amberes). Aunque, como es sabido, el libro fue prohibido en España el 17 de noviembre de 1553 y su prohibición duró largos años (en 1572 se ordenó recoger incluso los manuscritos originales que estuvieran en manos de los herederos), lo cierto es que tuvo gran diffusión y fue ampliamente utilizado dentro y fuera de España. En mi trabajo he utilizado preferentemente las siguientes ediciones, Francisco LÓPEZ DE Gomara: Historia de las Indias y Conquista de México. Zaragoza 1552, edición facsimilar, México, CONDUMEX, 1978; e Idem, Historia de la Conquista de México, edición crítica con introducción, notas y apéndice documental de Joaquín RAMíREZ Cabañas, 2 vols., México, Pedro Robredo, 1943.

(39) De todas las ediciones de la obra de López de Gómara la más completa es la primera, de 1552, porque incluye dos mapas y otros textos suprimidos en las demás ediciones. El análisis crítico muestra que Hernández usó sin duda alguna esa primera edición, como lo atestigua por ejemplo la utilización -en el Libro I, cap. 1- del mapa general de todas las Indias o la utilización -en el Libro I, caps. 20 y 25- de textos suprimidos en las otras ediciones (aparecen en los caps. 224 y 228 respectivamente de la Conquista de México de López de GOMARA).

(40) La cuestión de los manuscritos y ediciones de la obra de Sahagún es sumamente compleja. Para este trabajo he utilizado preferentemente Fray Bernardino de Sahagún, Códice Florentino. Historia general de las cosas de la Nueva España, edición facsimilar, 3 vols. México, (Florencia). Archivo General de la Nación (Casa editorial Giunti Barbèra), 1979.

(41) Hay múltiples referencias que lo demuestran pero pondré un sólo ejemplo. En el Libro I, cap. 2, dedicado a temas del parto, Hernández hace en breve resumen de los caps. 26 a 33 del Libro VI de la Historia Universal de Sahagún y después agrega una referencia más detallada del cap. 37 del mismo libro. Se trata de una invocación que la partera hace al "bautizar" al recién nacido; en esa invocación se menciona a los dioses "Ometeutli" y "Omecioatl", dioses cuyos nombres son omitidos por Sahagún en su traducción al castellano y que aparecen sólo en el texto náhuatl.

(42) "Fue traduzido en lengua española por el dicho Fray bernardino de Sahagun: después de treynta años, que se escriujo en la lengua mexicana: este año de mjll y qujnientos y setenta y siete", SaHaGún [41], vol. 2, f. $219 \mathrm{v}$.

\section{R. I., 1992, nos $195 / 196$}


Todos estos añadidos rompen la línea continua del desarrollo temático original y pueden percibirse con claridad. Hernández, en la primera versión de la obra, había estructurado los materiales de López de Gómara sobre un esquema propio basado en un modelo jurídico: primero lo civil, después lo penal... Ese modelo se alteró profundamente con la introducción de los nuevos materiales, llegando a transformarse la temática civil en todo un "ciclo de vida" de tipo antropológico, cuya exposición sin embargo ha quedado interrumpida en varias ocasiones por la presencia de otras temáticas distorsionadoras. Esto se debe a que la estructura original articulada a partir de lo civil y penal ha sido sólo parcialmente transformada en una exposición de lo que podríamos llamar la estructura social y política. Las dificultades para hacer esa transformación de una forma completa e integrada se originan, a mi parecer, en que Hernández utiliza un criterio clasificador muy complejo que le lleva a incluir en ese concepto de social y político todo lo que tiene que ver con lo "físico" o la cultura "material» (o lo «terreno», si se prefiere).

El Libro II está considerablemente mejor articulado, aunque el criterio unificador tampoco sea fácil de definir. Muy groseramente podría decirse que, frente a la preocupación por el hecho «material» de la vida social que era centro del Libro I, ahora Hernández se preocupa por los aspectos puramente "culturales" o de "civilización", en todos los sentidos que le podían preocupar a un humanista de la época: astronomía y medicina, el servicio a los «reyes» y a los dioses (incluyendo la música), la historia misma de los pueblos, la mitología y, por supuesto, la escritura y el calendario.

En el caso del Libro II, la integración de los materiales es bastante alta y muchas veces no resulta fácil definir con seguridad cuáles son las modificaciones o las propias ampliaciones textuales. Sin duda la fuente principal y base del texto "primitivo" vuelve a ser López de Gómara, pero hay también textos de Sahagún y además aparece una fuente no precisada (que en mi opinión es un texto muy próximo a Juan Bautista Pomar). No obstante, la idea total y parte misma de la información incluida es del propio Francisco Hernández. No por casualidad éste era el libro para el que se concibieron fundamentalmente - y se llegaron a realizar- las ilustraciones hoy perdidas, aportación que era una de los más originales y destacadas de la obra del protomédico. Hernández alude a esos dibujos en varias partes de su obra, pero la referencia más completa aparece en el Libro II, 
cap. 13, en el que al hablar de Nezahualcóyotl dice: «Su estatua, su escudo, banderas, trompetas, flautas, armas y otros ornamentos que acostumbraba usar tanto en la guerra como en los bailes públicos y que encontramos preservados con grandísimo respeto religioso, con el atabal con el que daba la señal de la acometida cuantas veces había que arrojarse sobre el enemigo, 0 tocaba retirada, he tenido cuidado de que fueran pintados para poner hasta donde yo pueda ante los ojos de nuestros hombres, las cosas pasadas y para que aquellos a quienes no ha sido dado ver gentes tan distantes, las conozcan en lo posible» (43). Esta especialísima preocupación por no sólo informar describiendo, sino también por mostrar "visualmente" en "fiel imagen", "con un dibujo exacto" -que incluso estaba acompañado por un pitipié o escala (44) - a fin de que en Europa se pudiera conocer "en lo posible» a "gentes tan distantes", es altamente expresiva de la peculiar formación científica de Hernández. El protomédico, incluso al describir las antigüedades del país, no actúa como un humanista filólogo sino como un científico renacentista, preocupado por la representación crítica no sólo del texto sino del propio objeto material que sirve para concretarlo.

Hernández, en este Libro II, domina mejor sus materiales textuales, los sabe mezclar con soltura y se atreve a opinar más y más veces. No es casual que, en esta ocasión, 12 de los 19 capítulos que aprovecha de la obra de López de Gomara aperezcan dispersos por el texto de la Historia de la Conquista y no concentrados monográficamente, como era el caso del apéndice etnográfico que aparece al final de ella. Lo mismo puede decirse de los materiales tomados de la obra de Sahagún, que el proto-

(43) Hernández, Antigüedades [30], pág. 115. Esta referencia básica es confirmada y detallada en otros dos lugares. En el propio Lib. II, cap. 6 (idem, pág. 96), al hablar de los diferentes instrumentos musicales - "el Hoehoetl y el teponaztli, género del tambor, flautas en su mayor parte de cañas, huesos cavados con muchas estrías y esferas huecas llenas de chinitas" dice: "De la mayor parte de estas cosas presentamos una fiel imagen para que sean conocidas y vistas por los españoles y por todas las otras naciones hasta donde pueda hacerse". Y en el libro I, cap. 20 (idem, pág. 66), al hablar de "un caracol o corneta" y de "un pequeño tambor" que eran utilizados en las acciones de guerra para dar señales al ejército, vuelve a insitir con respecto al segundo instrumento: "Nosotros lo vimos en Texcoco, preservado con grandísimo respeto con las vestiduras y demás ornamentos bélicos de Neçahoalcoyotzin y Meçahoalpilcintli, reyes de Texcoco, y el que cuidamos de reproducir, como otras cosas, con dibujo exacto".

(44) Para las expresiones de "fiel" y "exacto" véase la nota anterior; la referencia a la escala incluida en los dibujos aparece en la carta a Felipe II del 24 de marzo de 1576: "va expresado en la pintura el tamaño del natural" (MEDINA [4], pág. 286). 
médico supo ajustar y controlar para no alterar en exceso la claridad y estructura de su propio trabajo.

El Libro III, finalmente, es el que muestra una mayor coherencia en su desarrollo interno y en su propia temática. Se centra específicamente en la religión y la vida religiosa, pero dándole un tratamiento en el que se enfatiza la "acción humana» como fundamento y explicación de las peculiaridades de este fenómeno espiritual. Hernández no es original en este interesantísimo enfoque pues, aunque se ajuste a su propia línea de pensamiento, procede en realidad de una fuente privilegiada de información a la que tuvo acceso directo: el Sumario de 1570 remitido por Sahagún a Juan de Ovando.

En efecto, el protomedico no utilizó en esta ocasión a López de Gómara como base para escribir el texto "primitivo" de su Libro III. Hernández usó exhaustivamente un texto muy similar al Breve compendio de los rito idolátricos que fray Bernardino de Sahagún dedicó al Papa Pío V el 25 de diciembre de 1570 (45). Como es sabido, Sahagún había escrito previamente otro documento de características similares, que probablemente fue integrado en su totalidad -salvo la dedicatoria- en el Breve compendio y estaba fechado el 20 de mayo de 1570, a juzgar por una fecha que allí aparece (46). Este documento, hoy perdido, es conocido habitualmente como Sumario de 1570 y fue entregado al presidente del Consejo de Indias, Juan de Ovando, por mano de fray Jerónimo de Mendieta.

El análisis crítico del texto de Hernández demuestra que fue este documento, o una copia de él, el que estuvo en su poder y fue usado ampliamente. Así, los caps. 1-3 del Libro III se basan en un texto idéntico al del Breve compendio lo mismo ocurre con los caps. 6-13, que ofrecen además importantes precisiones críticas (47). Pero el caso más intereante aparece en el cap. 14, donde un texto inicialmente idéntico al del Breve compendio

(45) Conservado actualmente en el Archivo Secreto del Vaticano y publicado por el P. Livario Oliger en Antonianum n. XVII, Roma, 1942, págs. 3-38 y 133 174.

(46) Sahagún, Breve compendio [46], pág. 135.

(47) El ciclo de fiestas aquí descrito aparece no sólo en el Breve compendio, sino también en los primeros capítulos - sólo en castellano- del Libro II del Códice Florentino de Sahagún. Pero entre ambos textos hay pequeñas variantes, como la explicación de ciertos términos, la presencia de ciertos personajes o la mención a ciertos aspectos del ritual que sólo aparecen en el Breve compendio. Estas variantes aseguran que fue este ultimo, o el texto idéntico que aparecía en el Sumario, el utilizado por Hernández. 
incorpora al final una larga variante que asegura la existencia de otro original perdido (el propio Sumario remitido a Ovando)» (48).

Así, sobre la base de esta síntesis privilegiada y aprovechando su enfoque, Hernández compuso su propio texto, que no dudo en enriquecer con otras aportaciones extraídas de López de Gómara. Después agregó además algunos otros materiales sacados de la Historia Univeral de Sahagún, que simplemente vinieron a reforzar el enfoque inicial.

Resumiendo, cuando el protomédico recibió por encargo de Ovando la orden de llevar a cabo una "Historia Moral" complementaria de la "Historia Natural» que le había ordenado el Rey, lo que hizo fundamentalmente fue recopilar los materiales descriptivos de que ya disponía - la obra de López de Gómara y el Sumario de Sahagún-y estructurarlos en un esquema tripartito propio. Surge así el texto "primitivo» fijado en 1574. En ese texto, sin embargo, pueden observarse ya algunos aspectos muy originales. En en Libro III el protomédico afronta los fenomenos espirituales de una manera singular: los dioses son descritos y clasificados desde una perpectiva totalmente material y sociológica; otro tanto ocurre con las creencias escatológicas; y el resto de las cuestiones religiosas, finalmente, se centran en la descripción misma de los rituales, presentados como acciones sociales dirigidas a un fin.

Hernández acusa aquí la influencia de Sahagún y este Libro III se basa muchísimo en el Sumario escrito por el franciscano, cuyas ideas al respecto he estudiado en otro lugar (49). No obstante, esa influencia se ajusta muy bien a los planteamientos de Hernández mismo, cuya actitud "materialista" - propia de un naturalista - se refleja también en su tratamiento de las cuestiones "culturales» o de "civilización", que eran precisamente las que había decidido ilustrar a partir de objetos encontrados en su "trabajo de campo", adoptando así un metodo a medio camino entre el naturalista y el arqueólogo.

Tras la muerte de Juan de Ovando y sin que importe ahora

(48) Esa variante textual, con la descripción de fiestas semi-fijas y semimóviles, aparece también en el cap. 19 del apéndice al Libro II del códice Florentino de Sahagún que sin embargo, como atestiguan las variantes críticas que hemos mencionado en la nota anterior, no pudo ser la fuente de Hernández. El protomédico utilizó por tanto una tercera versión manuscrita del trabajo en castellano de Sahagún con la descripción resumida del ciclo de fiestas.

(49) Cfr. Jesús BustamanTE, "Retórica, traducción y responsabilidad histórica: claves humanísticas en la obra de fray Bernardino de Sahagún", en Berta ARES, Jesús Bustamante, Francisco Castilla y Fermín del PINo, Humanismo y visión del otro en la España moderna, Madrid, CSIC. (en prensa). 
precisar las causas que le impulsaron a hacerlo, el protomédico inició la remodelación de su escrito sobre las antigüedades. Para ello utilizó de forma masiva y como fuente casi única el gran texto escrito en náhuatl de fray Bernardino de Sahagún. El resultado, aunque algo confuso, es un reforzamiento notable de los criterios naturalistas-materialista ya presentes en la versión primitiva. Libre de las limitaciones formales impuestas por la solicitud de Ovando, Hernández recaracteriza la obra para integrarla a su proyecto de "Historia Natural». De esta manera, la «Historia Moral», la descripcion del hombre y de la cultura indígena mexicana, asumieron definitivamente la condición de un hecho "natural». El protomédico había dado el gran salto conceptual.

La justificación lógica de este planteamiento la proporciona Hernández mismo en el "proemio» de su obra: «juzgo que no distan tanto de ella [la "historia de las cosas naturales"] las costumbres y ritos de las gentes, porque aun cuando en gran parte no deban atribuirse al cielo y a los astros, puesto que la voluntad humana es libre y no está obligada por nadie sino que espontáneamente ejecuta cualesquiera acciones, todavía los más doctos de los filósofos opinan que hay concordia entre el alma y el cuerpo y mutua correspondencia entre el cuerpo y los astros; de modo que muy a menudo haciendo a un lado lo honesto y lo justo, sigamos las afecciones del cielo y del cuerpo y rara vez se encuentran quienes en contra de esos impulsos y de esa fuerza resistan firmes y tranquilos» (50).

Está claro que el protomédico era muy consciente del grave problema filosófico-moral a que daba lugar su planteamiento, por eso se apresuró a demostrar que a pesar de todo él se mantenía en la más pura ortodoxia católica y que su propuesta se ajustaba fielmente a lo que opinaban «los mas doctos de los filósofos». De hecho, Hernández reproduce aquí casi literalmente lo que dice sobre este tema el propio Santo Tomás de Aquino (51).

Pero aunque Santo Tomás le sirva de justificación, el protomédico no era un tomista precisamente. En este sentido es muy importante destacar la frase final de la cita anterior: "rara vez se encuentran quienes en contra de esos impulsos y de esa fuerza resistan firmes y tranquilos", pues se trata de una expresión estoica en su más puro estilo clásico. Esa frase proporciona así

(50) Hirnándiz., Anligḯedades [30], pág. 11.

(51) "Plures hominum sequuntur passiones, quac sunt motus sensitivi appetitus, ad quos cooperari possunt corpora coelestia", Summa, I, 115, 4. 
una clave importantísima para comprender la forma personal en que Hernández había tratado de resolver el problema filosófico, religioso y moral que desde su posición como naturalista le planteaba la relación entre el cuerpo y el alma, entre la naturaleza material y el espíritu. Se trata - a mi parecer- de una solución neo-estoica, la misma que se fue haciendo cada vez más dominante en la España de finales del siglo XVI y principios del XVII (asumiendo formas tan interesantes políticamente como la del tacitismo). En cualquier caso, alrededor de esta problemática fundamental que se le planteaba como naturalista es donde deben inscribirse precisamente los diferentes escritos de Hernández sobre cuestiones religiosas y morales, incluyendo esa sorprendente traducción de las obras de San Dionisio Areopagita.

Al margen de los problemas morales o filosóficos que de todo ello se derivaban, lo cierto es que con el apoyo de los propios Doctores de la Iglesia al protomédico le fue posible subrayar el componente material del ser humano e integrarlo además en un medio natural que lo condicionaba o modelaba.

Surge así la importancia de la teoría "ambiental» que aparece en múltiples lugares de la obra de Hernández. Un ejemplo, elemental pero muy claro, lo constituye todo el cap. 23 del Libro I, que trata precisamente "Del clima de la ciudad de México». El protomédico comienza describiendo a los naturales en los siguientes términos: "Los indios son en su mayor parte débiles, tímidos, mendaces, viven día a día, son perezosos, dados al vino y a la ebriedad, y sólo en parte piadosos..... Tan negro cuadro exigía una explicación y ésta, por supuesto, no radicaba en la naturaleza o constitución misma de los indios, sino en un condicionamiento ambiental que también podía extender su influjo negativo a todos los otros «naturales» de la tierra: «Ni las plantas echan profundas raíces, ni cualquiera es de ánimo constante y fuerte, y los hombres que nacen en estos días y que a su vez empiezan a ocupar estas regiones, ya sea que deriven su nacimiento únicamente de españoles o ya sea que nazcan de progenitores de varias naciones, ojalá que, obedientes al cielo, no degeneren hasta adoptar las costumbres de los indios».

Sin necesidad de continuar el análisis, estas citas reflejan ya un concepto básico que era bastante común en la época, casi obligado en un médico y que remitia en última instancia a la idea del hombre -en cuanto individuo- como microcosmos. Pero Hernández no se quedó en el lugar común, sino que en sus Antigüedades desarrolló considerablemente ese concepto y llegó 
a extenderlo a las realizaciones culturales y a la propia sociedad, que de este modo se transformaron también en un fruto producido por la Naturaleza. Las Antigüedades, por tanto, conducen en último término al ambicioso proyecto de "Historia Natural» planeado por Hernández y son en sí mismas un testimonio privilegiado de cómo la experiencia novohispana había influido en los planteamientos del protomédico.

Cabe así entender mucho mejor las consecuencias, con respecto a su trabajo, de una definición muy abstracta realizada por el propio Hernández: "La naturaleza es en dos maneras: una, de aquellas cosas que se mueven y pueden moverse; y otra, de las que ni se mueven ni pueden moverse, y como no se mueve cosa alguna que no sea cuerpo, el conocimiento de la disciplina cuyo subjeto es el movimiento tracta y fenece acerca del cuerpo movible» (52). En otras palabras, esa "disciplina cuyo sujeto es el movimiento" es la "ciencia natural» y la cita anterior es la definición de su objeto integral de estudio.

Hernández estuvo lejos de ser sólo un buen herborizador y un disciplinado recolector de materiales científicos. Esta definición teórica, cuyas delicadas implicaciones serán abordadas en otro lugar, así como el propio testimonio de las Antigüedades ponen de manifiesto la complejidad y el nivel intelectual que tuvo el gran proyecto naturalista del protomédico en la Nueva España. Queda pendiente, sin embargo, realizar un análisis crítico de los materiales conservados sobre la fauna y la flora que permita intentar la reconstrucción de su propuesta científica.

(52) Hernández [22], vol. VI, pág. 219. 


\section{Libro I}

Cap. 1. «Descripción general de todas las Indiasn. Es una visión cosmográfica general.

Caps. 2, 3, 4, 5 y 6. Inicia la descripción del ciclo vital, con todo lo que se refiere a la fase final del embarazo, el parto, "bautismo" y educación.

Caps. 7, 8, 9, 10 y 11. Prosigue el ciclo vital describiendo aquello que se refiere al matrimonio y poligamia, y termina transformándolo en lo puede llamarse el "derecho civiln: de las formas de heredar y de la esclavitud.

Cap. 12. Sobre la vivienda y la embriaguez. Lo civil se ha transformado en la descripción de la estructura social y politica.

Cap. 13 y 14. Se centra en lo que podríamos llamar la nobleza y la realeza: características, privilegios, consagración, vida cotidiana...

Cap. 15 y 16. Sobre la muerte y los rituales funerarios. Constituye propiamente el final del ciclo vital. Está dividida la exposición entre comunes y nobles.

Caps. 17, 18, 19 y 20. Prosigue con los temas de vida social y política: sobre el gobierno, las leyes y la guerra.

Caps. 21, 22, 23 y 24. Descripción de la ciudad de México en el momento de la conquista y después, de su clima y otras curiosidades.

Caps. 25 y 26. Descripción de los indios en general: su físico, vestido y costumbres que afectan a su apariencia externa, en la paz y en la guerra.
Se basa en Francisco López de Gómara, Historia de las Indias, caps. 11 y 12, y mapa anejo (sólo en la edición de 1552).

Se basa en F. L. de Gómara, Conquista de México, caps. 218 (para 2 y 5) y 219 (para 6). Posteriormente, el cap. 218 de Gómara fue sustituido en parte y muy ampliado con materiales sacados de Bernardino de Sahagún, Historia Universal de las Cosas de la Nueva España, especialmente Lib. VI.

El cap. 7 se basa también en Sahagún, Lib. VI; los demás en Gómara, Conq. Méx., cap. 220 (para el 8), 71 (para el 91), 212 (para el 10) y 226 (para el 11).

Se basa en Gómara, Conq. Méx., caps. 224 y 225.

Se basa en Gómara, Conq. Méx., caps. 214 (para el 13) y 213 (para el 14).

Se basa en Gómara, Conq. Méx., caps. 215 (para el 15, luego ampliado con textos de Sahagún, Lib. III, apéndice) y 216 (para el 16).

Se basa en Gómara, Conq. Méx., caps. 227 (para 18 y 19; muy ampliados con materiales de Sahagún, Lib. Vl, base del cap. 17 y parte del 18, y otra fuente no definida para cl cap. 19) y 228 (para 20, después ampliado con una fuente no definida).

Se basa en Gómara, Conq. Méx., cap. 78, después muy ampliado y comentado con observaciones personales de Hernández (particularmente caps. 22, 23 y 24).

Se basa en (jómara, Conq. Méx., caps. 222 y 223 (para cap. 25). Fuente desconocida para cap. 26. 
Caps. 27 y 28. Finaliza todo este ciclo descriptivo con los mercados, las mercancías que alli se venden y las muchas cosas de las que carecían antes de la llegada de los españoles.

\section{Libro II}

Caps. 1 y 2. La astronomía y la medicina indigenas.

Caps. 3, 4, 5, y 6. Las comidas y demás servicios que se hacía al "rey», así como de las diversiones.

Caps. 7 y 8. Servicios y dependencias del palacio «real».

Caps. 9 y 10. Descripción del templo mayor de México y de los sacerdotes.

Caps. 11, 12, 13, 14, 15, 16 y 17. Historia de los pueblos de México. Comienza con el problema de su origen, migraciones y asentamiento, y se extiende con la historia de Texcoco, México y Tlatelolco.

Caps. 18 y 19. Los augurios que tenían los mexicanos, seguidos de la leyenda de los cinco soles (Hernández pone al mismo nivel las abusiones y la mitología).

Cap. 20. De la escritura mexicana, sus números y signos calendáricos.

Libro III

Caps. 1, 2 y 3. De los dioses mexicanos y de su idea del origen del mundo.

Cap. 4. Descripción general del calendario solar y de los ciclos de 52 años.

Cap. 5. Descripción de los 20 signos del calendario adivinatorio de 260 días.

Caps. $6,7,8,9,10,11,12$ y 13 . El ciclo anual de fiestas del calendario solar.

Cap. 14. Fiestas móviles del calendario solar.
Se basa en Gómara, Conq. Méx., caps. 79 (para 27) y 224 (para 28), ambos ampliados con datos personales.

Es descripción personal.

La fuente básica es Gómara, Conq. Méx. caps. 67 (para 4), 68, 69 y 70 (para 5 y parcialmente, 6). Fuente desconocida para cap. 3 y la mayor parte del 6 (¿Pomar?).

La fuente es Gómara, Conq. Méx., caps. 72, 73,74 y 75 (para 7) y caps. 76 y 77 (para 8).

La fuente es Gómara, Conq. Méx., caps. 80 y 82 (para 9) y 229 (para 10).

Es una parte muy compleja de definir en sus fuentes. A un conjunto de investigaciones personales se añade una contribución no definida (¿Pomar?). Sobre ello, y conformando el conjunto, está Gómara, Cong. Méx., caps. 207, 208 (para 11), 209 (para 15) y 211 (para 16). Finalmente hay que añadir materiales de Sahagún, Lib. VII, caps. 1 y 6 (para 16) y 2 (para 17).

La fuente es Sahagún, Lib. V y su apéndice (para 18) y Gómara, Conq. Méx., cap. 206 (para 19).

Se basa en Gómara, Conq. Méx., caps. 200, 201, 203, 204 y 205, y un amplio comentario personal.

Se basa integramente en el Sumario de Sahagún de 1570, aunque conoce otros textos.

Capitulo eclectico. Utiliza a Sahagún, Lib. VII.

Capitulo ecléctico. Utiliza a Sahagún, Lib. IV (pero el mismo texto tambien en el Sumario) de 1570).

Se basa integramente en el Sumario de Sahagún de 1570.

Se basa en el Sumario de 1570 de Sahagún. 
Cap. 15. Descripción del año adivinitario de Se basa en Sahagún, Lib. IV. 260 días y sus suertes asociadas.

Caps. 16, 17, 18 y 19. Otras fiestas religiosas en diferentes lugares de México.

Salvo para el cap. 16, de fuente desconocida, los demás se basan en Gómara, Conq. Méx., caps. 238 (para 17), 237 (para 18) y 236 (para 19).

Cap. 20. Descripción de la ciudad de Tlax-

Se basa en Gómara, Conq. Méx., cap. 55. cala, asociada al último ritual descrito. 